\title{
DESIGUALDADES RURALES: EL IMPACTO DE LA CRISIS MULTIDIMENSIONAL EN LOS CAMPESINOS MEXICANOS
}

Carla Beatriz Zamora Lomeli ${ }^{1}$

\begin{abstract}
Resumen:
Este trabajo analiza los efectos de una crisis cuyas proporciones cobran múltiples dimensiones y genera severas consecuencias en los sectores más vulnerables del sector rural mexicano. Así, siguiendo una metodología de investigación cualitativa, se expone énfasis en la situación de los campesinos minifundistas con respecto a los grandes productores agroempresarios a través del análisis de las políticas públicas dirigidas al sector rural y su aplicación diferencial, lo que junto con el diseño de tales políticas, tal como se concluye, son elementos que abundan los efectos de la crisis y contribuyen a la profundización de las desigualdades en el campo mexicano.
\end{abstract}

Palabras clave: Campesinos, crisis, desigualdades sociales, nueva ruralidad, estrategias de sobrevivencia

\section{DESIGUALDADES RURAIS: O IMPACTO DA CRISE MULTIDIMENSIONAL NOS CAMPONESES MEXICANOS}

\section{Resumo}

Neste artigo, analisam-se os efeitos de uma crise cujas proporções ganham múltiplas dimensões e que gera severas consequências nos grupos mais vulneráveis do setor rural mexicano. Assim, seguindo uma metodologia de pesquisa qualitativa, dá-se énfase à situação dos camponeses minifundiários, distinguindo-a de aquela dos grandes produtores agroempresários. Através da análise das políticas públicas endereçadas ao setor rural, seu planejamento e sua aplicação diferenciada conclui-se que são elementos que agravam os efeitos da crise e contribuem ao aprofundamento das desigualdades no campo mexicano.

Palavras-chave: Camponeses, crises, desigualdades sociais, nova ruralidade, estratégias de sobrevivencia

\footnotetext{
${ }^{1}$ Becaria del Programa de Becas Posdoctorales en la UNAM. Instituto de Investigaciones Sociales, Universidad Nacional Autónoma de México. Doctora en Ciencia Social con Especialidad en Sociología, Email: chanumpom@yahoo.com.mx
} 


\section{INTRODUCCIÓN}

La cuestión rural ha sido un tema que los estudiosos de las ciencias sociales han investigado desde principios del siglo $\mathrm{XX}$, acercándose desde las diversas disciplinas sociales a la comprensión de los procesos que ocurren en el medio rural, y su interacción con el conjunto de la sociedad. En estos procesos, se dan cuenta de transformaciones que impactan en quienes habitan en el medio rural y en sus interacciones cotidianas, donde emergen procesos de urbanización que implican un cambio en las relaciones rural- urbano, imponiendo dinámicas de poder donde la relación dominante se concentra en el polo urbano, y que se manifiesta en la colonización territorial, la terciarización de la economía, y la marginación económica y social de los sectores rurales.

En dicho escenario, la brecha de las desigualdades sociales se ha ampliado cada vez más, donde los antagonismos entre lo urbano y lo rural han dejado un saldo negativo para la vida del campo, y al mismo tiempo, se amplía la brecha entre pequeños y grandes productores agropecuarios con respecto a las ventajas en el mercado. Particularmente, en la dinámica rural se encuentra que el agravamiento del modelo agrícola de producción, respecto a sus formas para obtener ingresos a través de la producción de materias primas, aunado a la expansión urbana y a los efectos del cambio climático, han hecho de la campesina, una economía de sobrevivencia, que frente a estas problemáticas, responde a partir de la diversificación de los ingresos para las familias rurales, la modificación en los patrones culturales, y las transformaciones en la interacción entre lo urbano y lo rural inmerso en los fenómenos propios de la nueva ruralidad.

Así, asistimos a un contexto de crisis que se expresa en todas las dimensiones de la estructura social, una crisis multidimensional que es aquella "cuya radicalidad proviene de que se están cerrando tres ciclos: el patrón neoliberal de acumulación, el capitalismo como modo de producir y la sociedad urbanoindustrial como orden civilizatorio" (BARTRA, 2010). Se trata de una crisis derivada del agotamiento del modelo de producción y consumo cuyo impacto trasciende las esferas de lo ambiental, social, económico, político e incluso moral.

En este sentido, se hace preciso reflexionar sobre las implicaciones de la crisis a partir de las transformaciones obligadas en el entorno rural, considerando las conceptualizaciones tradicionales sobre el campesino, a la luz de las expresiones de la nueva ruralidad y los escenarios que se presentan en medio de la crisis, lo cual constituye el objeto de este trabajo.

\section{MÉTODO}

Para realizar esta investigación, se utilizaron instrumentos teórico metodológicos en su mayoría cualitativos como la observación participante en organizaciones campesinas y entrevistas no estructuradas a sujetos clave en el periodo de mayo a diciembre de 2014, así como revisión bibliográfica y hemerográfica que permitiera tener datos actualizados sobre el tema, como parte de la investigación realizada durante la estancia posdoctoral en el Instituto de Investigaciones Sociales de la Universidad Nacional Autónoma de México.

De esta manera, se trata de una investigación de carácter mixto, que combina elementos cualitativos y cuantitativos. Lo anterior se refiere a la utilización de métodos interconectados para generar información sobre el objeto de estudio (los pequeños productores rurales), y combina el abordaje de trabajos empíricos que 
describen rutinas y significados de los sujetos que no son medibles, con la interpretación de datos estadísticos básicos que apoyan también la descripción del hecho social.

Metodológicamente, es una investigación con variables cualitativas y cuantitativas, inferencial y con un diseño de tipo longitudinal de tendencia (es decir, refiere al análisis en diferentes momentos), en el cual las unidades de análisis se fundan en la economía campesina y colectiva (organizaciones y grupos), aunque propiamente no se concentra en un estudio de caso en particular, sino presenta una dimensión deductiva que tiende al análisis a nivel nacional.

Con esta base, podremos acercarnos directamente al sujeto de estudio, y recuperar la riqueza de la información de primera mano que habrá de complementarse con la revisión documental de fuentes de secundarias (artículos periodísticos, material audiovisual, folletos, archivos históricos, etc.).

\section{RESULTADOS Y DISCUSIÓN: UN ACERCAMIENTO A LA CONCEPTUALIZACIÓN DEL CAMPESINO}

Tradicionalmente, se ha estudiado al campesino desde un concepto que lo concibe como el productor de materias primas y alimentos para la sociedad, que está en contacto con su medio de producción (la tierra), emplea mano de obra familiar, y tiene una organización social, política y cultural propia ${ }^{2}$.

Asimismo, durante las décadas de los sesenta y setenta, los estudiosos de lo rural en México, sostuvieron un debate en torno al campesino como modo de producción, identificando la composición de dos grupos: los minifundistas (pequeños propietarios) y los asalariados rurales sin tierra (proletarios agrícolas) (FEDER, 1977), considerando al mismo tiempo, que la mano de obra campesina podía pertenecer a ambos grupos por su naturaleza polivalente. El debate que se basaba en la escuela del materialismo histórico dialéctico, distinguía también a una clase social como burguesía agraria (poseedores de grandes extensiones territoriales), con lo que se tiene una primera aproximación a la estructura de clases sociales en el campo.

Sin embargo, el concepto del campesino en su acepción tradicional, ha ido cambiando debido a la naturaleza de las transformaciones estructurales donde el campesino se desdibuja con respecto a su dedicación a las actividades agrícolas, y se da paso a otro tipo de actividades económicas que no dependen del trabajo con la tierra. De este forma, lo campesino como concepto, se suscribe con una fuerte relación con respecto a lo identitario, toda vez que la identidad campesina forma parte de la subjetividad de los individuos, cuyas relaciones sociales se basan en las nociones de pertenencia con respecto a la tierra o el territorio, se encuentran relaciones parentales estrechas, y se percibe la reproducción de un marco cultural con rituales y símbolos anclados en lo comunitario, es decir, aun cuando económicamente no dependan de la actividad agrícola, los campesinos mantienen su identidad desde lo social y cultural, e incluso, lo político.

De esta forma, Hubert Carton (1995) apunta que la relación de los campesinos con la tierra tiene tres niveles sobre los que se fundan las demandas agrarias: el económico (la explotación de la tierra para la producción de alimentos) el ideológico (en tanto referente para la construcción social) y el simbólico (como elemento cohesionador de la comunidad desde la identidad), es decir, los niveles de

\footnotetext{
${ }^{2}$ Definición propia con base en: WOLF (1975), y FEDER (1977).

${ }^{3}$ Al respecto pueden verse entre otros: FEDER (1977) y BARTRA et. al. (1979).
} 
relación de las sociedades con la tierra son más profundos que en sociedades no rurales. Además, a partir de la identidad campesina, puede tener lugar la emergencia de acciones colectivas ${ }^{4}$ donde se encuentran también elementos políticos, como ocurre en el caso de la lucha por la tierra, pero además, son fenómenos que se presentan desde la resistencia y el conflicto inherentes a las relaciones de poder.

Ello implica entender al campesinado como

\begin{abstract}
el agregado social compuesto por pequeños productores agrícolas que, con la ayuda del trabajo de sus familias y el equipamiento simple, producen principalmente para su propio consumo y para atender las obligaciones que tienen para quienes detentan el poder político y económico. Esta definición implica una específica relación con la tierra, con la explotación agrícola familiar y con la comunidad campesina como unidades básicas de interacción social, una característica estructura ocupacional, una particular influencia del pasado y unas específicas pautas de desarrollo (GONZÁLEZ, 1992 p. 67).
\end{abstract}

Al respecto de esta definición, acotamos también que el carácter del autoconsumo y la sobrevivencia del campesinado, se ha ido transformando por las propias necesidades de reproducción social del campesinado, que a su vez, se conciben como estrategias de sobrevivencia campesinas.

De este modo, las estrategias de sobrevivencia campesinas refieren a "ciertas modalidades que adquiere la producción y reproducción social de la existencia de los pequeños productores rurales como respuesta al medio ambiente natural y social con el que interactúan en la vida cotidiana" (ALLUB, 2000). En otros términos, las estrategias de sobrevivencia campesina implican el análisis de los procesos de reproducción social y económica de los pequeños productores rurales, en tanto que se refieren a los comportamientos de los agentes sociales que se relacionan con la constitución y mantenimiento de sus unidades familiares en el seno de las cuales pueden asegurar su reproducción biológica, preservar la vida y desarrollar todas las prácticas económicas y no económicas, indispensables para la optimización de las condiciones materiales y no materiales de existencia de la unidad y de cada uno de sus miembros.

Así, las estrategias de sobrevivencia campesina tienen la particularidad de que a pesar de la diversificación de actividades o el cambio en los mercados de trabajo, existe un vínculo con relación a la tierra que determina la categoría a que corresponde la estrategia, al mismo tiempo, la calidad de la tierra es un elemento que incide en la opción por estrategias de sobrevivencia, toda vez que a mejores condiciones del terreno, teóricamente habría mayor arraigo a la actividad campesina dadas las condiciones de fertilidad e irrigación para la producción agrícola, como apunta el supuesto marxista de la renta diferencial de la tierra. En caso contrario, ante la carencia de condiciones para la producción, y particularmente de mercado, los productores recurren a la pluriactividad para complementar sus ingresos, fenómeno que ha sido estudiado desde el siglo XIX en Europa por Kautsky (1974).

No obstante, las condiciones estructurales del mercado no ofrecen las mismas oportunidades para todos los productores agrícolas, pues depende de la demanda de los productos, el precio de producción, la extensión de la tierra, y el

\footnotetext{
${ }^{4}$ De acuerdo con Sidney Tarrow (1994), las formas de acción colectiva son histórica y sociológicamente distintivas, y tienen poder porque desafían a sus oponentes, despiertan solidaridad y cobran significado en el seno de determinados grupos de población, situaciones y culturas políticas
} 
empleo de tecnología y maquinaria agrícola, para que las ganancias de un productor agrícola puedan ser un motor de desarrollo económico y social.

Ello se ha observado a lo largo de la historia en México, en un campo donde tienen lugar relaciones de poder, y se encuentra que "la historia rural mexicana ha sido consecuencia constante de explotación e injusticia entre quienes poseen la tierra y los medios de producción y los que la hacen producir con su trabajo sin participar de los beneficios de sus frutos. La historia se ha repetido incesantemente en épocas y situaciones diferentes desde la colonia hasta la actual época postrevolucionaria. En todas las etapas del desarrollo mexicano, una minoría privilegiada ha detenido el poder y la riqueza en las zonas rurales como producto de la explotación del trabajo de la mayoría que sobrevive en condiciones socioculturales de extrema miseria" (Op. Cit. p.45), tal es el impacto también de una crisis estructural que incide directamente en los pequeños productores agropecuarios, como a continuación se observa.

\subsection{Desigualdades sociales y políticas públicas para el sector rural}

La manifestación de la crisis multidimensional de las últimas décadas en el campo mexicano, ha dejado a los pequeños productores rurales en una vulnerabilidad abierta frente al modelo de producción y consumo a escala global, donde prevalece la lógica dominante de la economía global y el libre mercado, y por ende, los campesinos son sistemáticamente excluidos para dar paso a la producción masiva de alimentos desde la biotecnología, la explotación intensiva de recursos naturales por parte de consorcios empresariales, y una marginación social que observa a los pequeños productores rurales como sujetos de beneficencia pública, negando su carácter social.

Estas tendencias, han sido producto, entre otras cosas, de una fuerte ruptura del pacto corporativo postrevolucionario entre el Estado y los campesinos, donde al final de cada año, las organizaciones campesinas desfilan en la pasarela del Congreso de la Unión contemplando el pastel de recursos públicos a distribuir mediante los programas de gobierno, que en todos estos años, han tenido escaso impacto en la reactivación del campo mexicano, particularmente en los últimos dos sexenios, donde la aplicación de las políticas públicas de corte social que pretenden atender los efectos de la pobreza, se coloca por encima de las políticas que impulsen la producción de los pequeños productores agrícolas, como se observará posteriormente.

Conviene mencionar, que los procesos de reforma agraria (1917-1992), trazaron a grandes rasgos la diferenciación productiva del territorio nacional con base en la redistribución de la tierra, y establecieron una distinción que todavía está presente en las tierras de propiedad privada -caracterizada por la agricultura comercial/ empresarial, con inversión en tecnología y riego, conformada por unidades económicas de tamaño viable- y las tierras sujetas al régimen ejidal y comunal asociados a la economía campesina (APPENDINI et. al. 2008, p. 14). Además, las diferencias regionales están marcadas también por graves desigualdades regionales que inciden en los habitantes de las regiones, como puede observarse en la región suroeste de México, donde se concentran los índices más altos de marginación y los menores índices de desarrollo humano, pero también donde habitan la mayor proporción de pequeños productores rurales y grupos indígenas, y se encuentra una amplia riqueza de recursos naturales, tal geografía puede observarse en el siguiente mapa: 
Imagen 1 - México. Grado de marginación por entidad federativa, 2010.
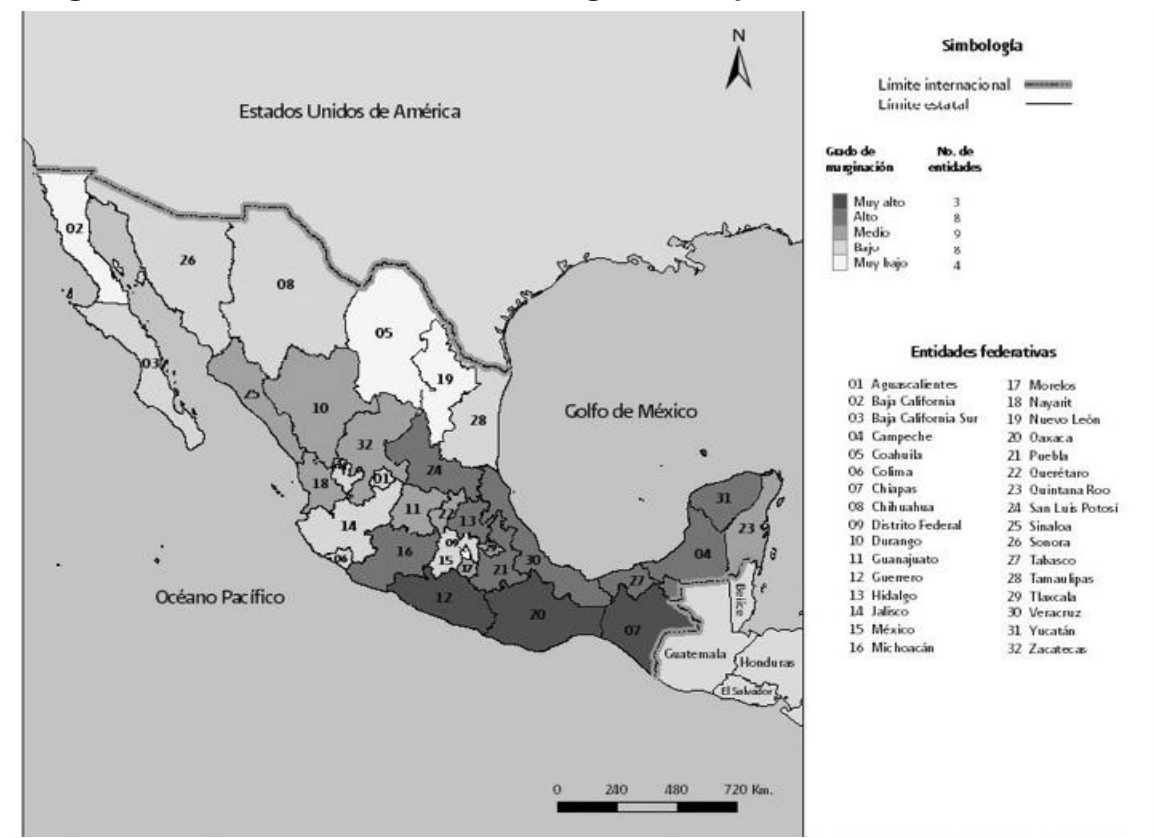

Fuente: Consejo Nacional de Población, 2010

Así, las desigualdades entre los productores agrícolas distinguen entre aquellos productores que destinan la tierra para la producción comercial y cuentan con infraestructura e insumos tecnológicos (generalmente poseedores de propiedad privada o arrendatarios), de aquellos productores que carecen de recursos para incentivar la producción, cultivan productos básicos en tierras de temporal, y tienen propiedad de tipo social, ubicadas principalmente en el centro y sur del país.

De lo anterior, se desprende que el indicador que determina el tamaño de la producción agrícola, es la extensión de las parcelas o de las superficies que se utilizan para esta actividad. De acuerdo con el Censo Agropecuario y Ejidal más reciente, en 2007 en México existían 6.4 millones de unidades de producción agrícola (UPA) ${ }^{5}$, de las cuales 3.7 millones tenían una superficie de tres hectáreas ó menos, en tanto que el promedio de extensión de las superficies de las UPA es de ocho hectáreas. En estas unidades de producción, las destinadas a actividades agropecuarias y forestales ocupan 112.7 millones de hectáreas, es decir, el $57.5 \%$ de la superficie total del país. Asimismo, la superficie agrícola en el país asciende a 30.2 millones de hectáreas, de las cuales 13.9 millones estuvieron ocupadas por cultivos anuales, y 3.7 millones declararon tener actividad agrícola. De éstas, el $10.8 \%$ dispone de sistemas de riego; $83.0 \%$ es de temporal y $6.2 \%$ combina áreas de riego y áreas de temporal (INEGI, 2007), con lo cual es notorio que el campo mexicano carece en buena medida de sistemas hídricos para la producción de alimentos.

\footnotetext{
${ }^{5}$ De acuerdo con el INEGI (2007), una unidad de producción, es un conjunto formado por los terrenos con actividad agrícola en el área rural o urbana, ubicados en un mismo municipio, manejados bajo una misma administración.
} 
En otros términos, existe un sector mayoritario de pequeños propietarios que se dedican a la actividad agrícola de temporal y que carecen de infraestructura para la producción comercial a gran escala. De esta manera, se puede considerar que todos los productores que estén dentro de estas UPA con tres o menos hectáreas desarrollan una producción de pequeña escala, se denominan pequeños productores o minifundistas. Debido a que estos productores constituyen más de la mitad del total de las UPA, carecen de infraestructura para la producción como los sistemas de riego, y producen cultivos que escapan a los estándares de exportación, resulta la importancia, pertinencia y relevancia de potencializar este segmento de la producción agrícola nacional.

Además, existe una tendencia histórica que ha sido constantemente impactada por crisis recurrentes. De este modo, la dinámica productiva y económica del agro mexicano sufrió un cambio sustancial desde finales de la década de los años sesenta, ya que el ritmo de crecimiento del valor de la producción agropecuaria cayó a menos de la mitad en el periodo de 1966 a 1979, lo cual, aunado al crecimiento poblacional, significó que hacia mediados de los años setenta, la agricultura dejara de ser uno de los principales proveedores de divisas a la economía mexicana.

Posteriormente, en la década de los ochenta inició la puesta en marcha de reformas económicas orientadas hacia la liberalización del mercado, en las cuales el Estado comenzó a limitar su intervención. Hacia la década de los años noventa, el gobierno mexicano realizó la modificación al artículo 27 constitucional en 1992, lo cual ha sido uno de los detonantes más importantes de las transformaciones a nivel macro en el campo, toda vez que con dicha reforma se concluye la redistribución de la tierra, se establece la libertad de decisión y de gestión de los ejidos y de sus integrantes, se concede definitividad a los derechos individuales de los ejidatarios, y se establece la opción de cambio en el sistema de propiedad ejidal, impulsando el mercado de tierras y su uso como garantía para el crédito. Para entonces, también

\begin{abstract}
los productores [quedaron] fuertemente mermados en sus posibilidades de capitalización tras sufrir los efectos de una década de disminución de los recursos destinados al campo. Los campesinos quedaron excluidos cuando se aplicó el modelo que exigía competitividad en el mercado interno y externo (YÚNEZ 2010, p.24).
\end{abstract}

Con la firma del Tratado de Libre Comercio con América del Norte (TLCAN) en 1994, se terminaron de abrir las fronteras para la libre competencia comercial internacional, en donde el campo mexicano se ha encontrado en desventaja de condiciones e infraestructura para competir con otros países.

Por otra parte, el impacto de las reformas estructurales en el campo recae especialmente sobre quienes poseen el $52 \%$ del territorio nacional en propiedad social. En estas propiedades, se encuentran 31 mil 623 núcleos agrarios, de los cuales 29 mil 240 son ejidos y 2 mil 383 comunidades. Estos mismos territorios, son los principales excluidos del proyecto de desarrollo económico nacional, pues es aquí donde prevalece la marginación y la pobreza extrema.

Esto se expresa en el reparto de los recursos públicos para el campo, donde se observa que la apuesta gubernamental se torna hacia el ámbito social recurriendo a los subsidios a través de estrategias de combate a la pobreza, que si bien son un fuerte componente en los ingresos de las familias que viven en esta situación, no han sido un detonador para procesos de desarrollo regional que 
representen cambios significativos en la estructura de las desigualdades sociales, por lo que predomina la marginación, la discriminación y la exclusión social.

Concretamente, en palabras de Zarazúa (2011), los cambios de las últimas décadas en la estrategia gubernamental hacia el sector rural, pasaron de una política de control de precios basada en el monopolio estatal de la importación, los precios de garantía, los bienes públicos y las empresas paraestatales que apoyaban con fertilizantes, semillas, y seguro agrícola, a medidas de política pública desreguladas y dominadas por las fuerzas del mercado internacional que reducen drásticamente los apoyos para bienes públicos.

Es así que el Estado paulatinamente ha ido disminuyendo su intervención en el campo, concentrándose en la apertura a la competencia internacional, y ofreciendo paliativos a los pequeños productores para los cubrir los costos sociales del abandono al campo.

En concreto, como puede observarse en la siguiente gráfica, elaborada por el Programa Estratégico para la Seguridad Alimentaria (PESA) de la FAOSAGARPA con base en su padrón de beneficiarios, demuestra que buena parte de los ingresos rurales provienen de los subsidios gubernamentales, es decir, que existe un margen significativo de dependencia respecto a estos incentivos:

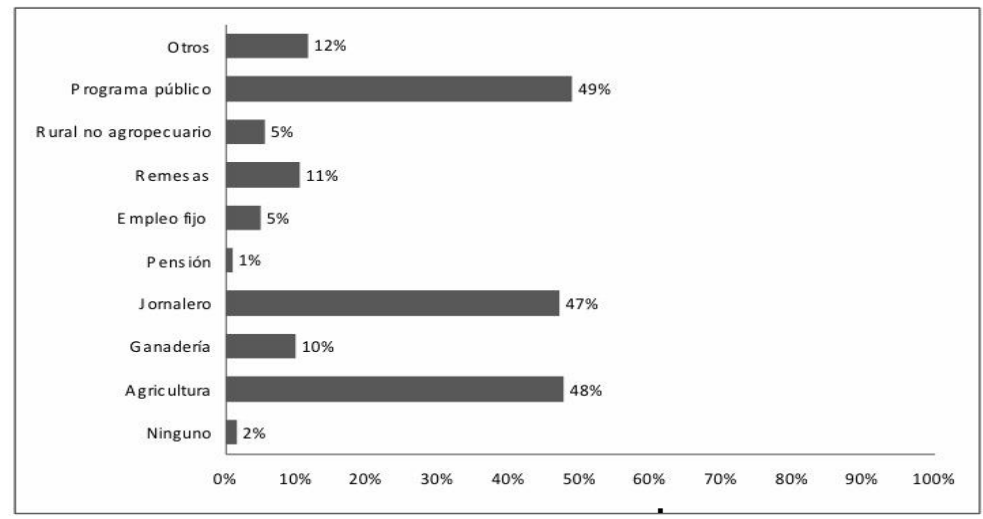

Cuadro 1 - Fuente de ingresos de beneficiarios PESA, 2012.

Fuente: Sagarpa- FAO, Programa Estratégico para la Seguridad Alimentaria, México, 2012

Acorde con lo anterior, los subsidios gubernamentales a la población representan una parte importante para las familias que dependen de éste, lo que además de implicar un alto costo financiero, no logra subsanar los problemas de origen que generan desigualdad social y pobreza. Lo anterior debido a que si bien las evaluaciones externas que corresponden al programa Oportunidades (hoy llamado Prospera, programa de inclusión social) han reportado avances paulatinos en materia de salud, nutrición, y educación, dichos apoyos no han mejorado sustantivamente la calidad de vida de las familias más pobres, es decir, que los efectos de la crisis económica y social son superiores a las estrategias de combate a la pobreza, por lo cual han aumentado el número de pobres, y por consiguiente, la brecha de desigualdades sociales continúa ampliándose.

Así, la reestructuración de la política agropecuaria se encuentra estancada, lo que se traduce en palabras de algunos economistas, como una disminución en términos reales del gasto público para el sector, lo que ha repercutido en el agravamiento de las condiciones de los pequeños productores rurales, pues "de 1982 a 1989, el gasto público en agricultura disminuyó en un $67 \%$ en términos 
reales, y representó solamente un $5,4 \%$ del total del gasto público"(APPENDINI, et. al., 2006, p. 8); aunque cabe destacar que desde el año 2000, se han reportado aumentos sustantivos en el presupuesto destinado al campo, aunque ello no ha logrado elevar la producción de alimentos para el consumo interno o propiciar condiciones de mercado donde puedan competir todo tipo de productores agrícolas, dado que "mientras que en 1980 la dependencia del país en alimentos era del $15 \%$, en 2009 fue de $42 \%$ : 33\% del maíz, 50\% del trigo, 70\% del arroz, 97\% de la soya, $20 \%$ de la carne de res, $33 \%$ de la carne de cerdo, $14 \%$ de la carne de pollo, $13 \%$ de la leche" (BARTRA, 2010, p. 53).

En este sentido, conviene resaltar que algunos factores que contribuyen a estas desventajas en el mercado, son la suspensión de los precios de garantía, así como la venta o liquidación de las instituciones paraestatales de apoyo a la agricultura, y la apertura a la importación de cultivos básicos, lo cual ha repercutido en la caída de los precios agrícolas.

En consonancia, en 1991 se creó la institución de Apoyos y Servicios a la Comercialización Agropecuaria (ASERCA). De esta manera, el sector público indujo la concertación de precios entre grandes compradores y productores usando apoyos a la comercialización, aunque solamente se concentró en algunos productos y en regiones con grandes excedentes. Por ese motivo, no representó la compensación que se necesitaba para los precios de garantía, por lo que se creó el Programa de Apoyos Directos al Campo (PROCAMPO) que ha sido el instrumento más importante de política sectorial para la agricultura (ZARAZÚA, 2011, p. 33).

De esta manera, desde su creación, el PROCAMPO ha sido uno de los programas más populares del gobierno federal para el campo, el cual ejerce más de la tercera parte de los recursos orientados al desarrollo agropecuario administrados por la Secretaria de Agricultura, Ganadería, Desarrollo Rural, Pesca y Alimentación (SAGARPA). Este programa, siguiendo a Zarazúa (2011), tiene como objetivo la transferencia vía subsidios, para compensar la pérdida de ingresos de los productores agropecuarios frente a las desventajas de la apertura comercial y la falta de precios de garantías, promoviendo al mismo tiempo la reconversión productiva hacia actividades de mayor rentabilidad; el estímulo para la organización de productores; la competitividad de las cadenas productivas, y el apoyo a proyectos ecológicos.

No obstante, el alcance de los objetivos del PROCAMPO ha sido lento, en tanto no se ha incidido en un aumento significativo de los ingresos para los pequeños productores, ni en el aumento de los rendimientos por cosecha. Además, a lo largo del ejercicio del PROCAMPO se han encontrado múltiples indicadores de corrupción, ${ }^{6}$ lo cual contribuye a disminuir el impacto del programa en términos reales.

Por otra parte, otro programa no menos importante para el sector rural, lo constituye Alianza Contigo, el cual comenzó a operar desde 1996 bajo el nombre Alianza para el campo, y consiste en el apoyo a proyectos específicos de

\footnotetext{
${ }^{6}$ Durante 2002, se dio a conocer que "tres mil productores de Chiapas recibieron entre 43 y mil pesos de ayuda, mientras que en los estados de Tamaulipas, Zacatecas, Sinaloa, Sonora, Chihuahua, Durango y Guanajuato, hubo personas que, por sus extensiones de tierra, obtuvieron cantidades que superan por mucho los 100 mil pesos estipulados", con lo cual se transgredian las reglas de operación que establecían como tope mínimo de ayuda mil 300 pesos y máximo 100 mil; por otra parte, en 2010 se encontró que algunos de los beneficiarios del programa, eran "ex funcionarios, poderosos agroindustriales y personajes relacionados con el crimen organizado", mientras que funcionarios de SAGARPA declaraban que "Ios niveles de corrupción en programas de apoyo a los agricultores han propiciado que una persona haya cobrado 84 veces el apoyo que una sola vez debió recibir". Al respecto puede verse: RAMOS 2002, y HERNÁNDEZ, 2010.
} 
productores que se asocian y aportan la tercera parte de la inversión; y se centra en dar impulso al desarrollo tecnológico, el pequeño riego y la reconversión productiva, sobre todo por lo que se refiere a la adaptación de tierras marginales de labor a pastizales. Alianza Contigo tiene un componente social en el marco de la política de erradicación de la pobreza, que consiste en otorgar créditos a pequeños proyectos productivos (APPENDINI, 2006, p.8); sin embargo, distintas las evaluaciones externas al programa, han reportado desfases en los periodos de ejecución del programa y bajo impacto en el desarrollo de cadenas productivas y la generación de valor agregado, el fortalecimiento organizativo, el mejoramiento de capacidades y asistencia técnica, y el incremento de la producción como resultado de una estrategia articulada, asimismo, en términos reales los pequeños productores minifundistas difícilmente son sujetos de crédito para obtener la liquidez necesaria en el esquema de coinversión que implican estos programas.

Dicha tendencia también se observa al analizar los componentes de capitalización promovidos por los programas públicos de la Secretaría de Agricultura, Ganadería, Desarrollo Rural, Pesca y Alimentación (SAGARPA), donde, en palabras del investigador Héctor Robes (2012):

\begin{abstract}
en las entidades con mayor índice de capitalización (predios grandes, con riego y equipados) se ejerció un mayor presupuesto. En conclusión, los apoyos productivos los concentran los productores con mayores predios $y$ capitalizados que se localizan en el norte del país (Tamaulipas, Sinaloa, Baja California, Chihuhua y Sonora) mientras que los productores minifundistas que son la mayoría reciben muy pocos apoyos. La mayoría de los programas de SAGARPA tienen muy baja cobertura, lo que se puede observar al comparar el programa principal de esta institución contra las Unidades de Producción (UP) con actividad agrícola que registró el Censo Agrícola Ganadero 2007. Los beneficiarios Procampo suman 2.1 millones mientras que las unidades de producción agrícolas son 3.7 millones, lo que da una cobertura del $57 \%$. Resalta que es en los estados con mayores rezagos sociales y económicos donde se encuentran las coberturas más bajas (ROBLES, 2012, p. 3).
\end{abstract}

Lo anterior se expresa en la siguiente gráfica:

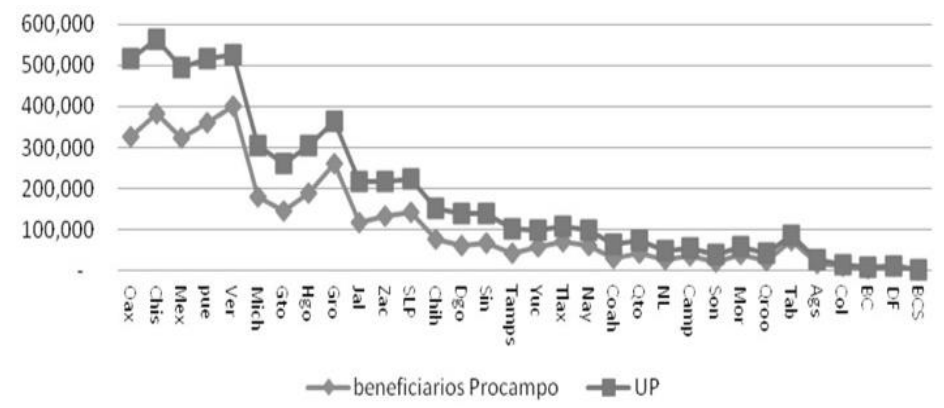

Cuadro 2 - Comparativo de unidades de producción y beneficiarios de Procampo. Fuente: Robles, H. 2012. 
Finalmente, los programas que derivan de las políticas públicas destinadas al sector rural, en muchos casos tiene las reglas de operación poco claras que escapan a las posibilidades de muchos campesinos, y por otra parte, en la distribución y acceso a los recursos, se encuentra en otros casos el privilegio por el apoyo a las organizaciones aliadas del gobierno federal o local, con lo cual las políticas tienen un uso corporativista y clientelar, en diseños que generalmente se terminan o modifican con cada cambio de administración gubernamental.

En consecuencia, en el sector rural se han generado políticas que atienden a la asistencia social para el combate a la pobreza, más que al impulso económico productivo de los pequeños productores, con lo cual se observa una tendencia hacia el abandono de las actividades agrícolas en pequeña escala, el aumento de la migración, la pobreza extrema, el desgajamiento del tejido social en las comunidades rurales, y el agotamiento de la tierra y los recursos naturales en los espacios aledaños a las comunidades.

\subsection{La crisis multidimensional y su paso por el campo}

Al observar el paso de la crisis multidimensional por el campo mexicano, los desastres naturales y sociales se estiman con un impacto lacerante. La pobreza extrema se acentúa entre el $25 \%$ de la población que habita en zonas con menos de 2,500 habitantes, zonas rurales donde los procesos sociales se conciben desde el trabajo diario con la tierra, desde las fiestas y tradiciones que se marcan con los calendarios, desde las lenguas indígenas de quienes habitan los territorios rurales.

Estructuralmente, la crisis del campo ha impactado en los estratos marginados de la sociedad, y concretamente en el campo, han sido los pequeños productores campesinos, los jornaleros agrícolas con y sin tierra y los asalariados rurales quienes han vivido las consecuencias de un modelo económico orientado hacia el mercado. Una muestra de los saldos de la crisis a nivel macro, ha sido el paulatino incremento la dependencia agroalimentaria: la brecha entre importaciones de granos y el total de la producción interna se ha agrandado, mientras el flujo migratorio de los campesinos hacia las ciudades centrales y transfronterizas ha ido en aumentado.

De manera general, siguiendo el esquema de Armando Bartra (2010), la crisis multidimensional se expresa en el campo mexicano bajo las siguientes dimensiones y problemáticas:

- Económicas y productivas: entre estas se encuentra la mala calidad y el bajo rendimiento de la tierra (en otros términos, erosión y degradación de los suelos); la elevación de los precios de los alimentos y la falta de garantías en los precios básicos; la carencia de infraestructura y tecnología para la producción rural; la falta de créditos para la producción; así como la falta de insumos para ingresar en la competencia de los mercados internacionales.

- Sociales y demográficas: en estas se encuentran la migración y la caída de las remesas enviadas a México; la incidencia del narcotráfico en los patrones de cultivo y posesión de las propiedades agropecuarias, así como la escalada de violencia e inseguridad en el contexto de la estrategia gubernamental de combate al narcotráfico; la pobreza extrema; los bajos niveles educativos; la carencia de servicios públicos en las comunidades 
rurales; la mala nutrición; la falta de oportunidades escolares y laborales para los jóvenes; y el trato discriminatorio hacia las mujeres a través de prácticas violentas que atentan contra la integridad física y psicológica de las mujeres a nivel familiar y comunitario.

- Políticas: entre estas problemáticas se encuentra la desconfianza ciudadana; los cacicazgos locales; la falta de información política para el ejercicio del voto libre y secreto; y en algunas localidades, la ingobernabilidad asociada a la presencia de grupos armados que actúan fuera de la legalidad (paramilitares).

- Ambientales: esta dimensión se cuentan como efectos del cambio climático, y pueden presentarse como grandes periodos de sequía y desertificación; inundaciones; aumento de la temperatura; contaminación de ríos, lagunas y mares; pérdida de la biodiversidad; y agotamiento de la calidad de los suelos.

En México habitan 112, 322, 757 personas. De ellas, una de cada cuatro habita en localidades rurales, mientras que el $12.3 \%$ de la población económicamente activa, se dedica a las actividades agropecuarias como principal fuente de ingresos (INEGI, 2010), por lo tanto, la importancia de la población rural y su contribución a la economía nacional no son menores.

Evidentemente, este sector de la población no constituye un grupo heterogéneo, pues a lo largo del territorio nacional se presentan múltiples realidades que varían de acuerdo a los procesos históricos locales, las condiciones geográficas, la vocación productiva de la tierra, y los patrones culturales. Sin embargo, a pesar de esta diversidad, conviene destacar la existencia de patrones sociales donde es posible encontrar condiciones similares con respecto a la propiedad de la tierra, así como significados culturales alrededor de la misma, los cuales son un eje de la cohesión identitaria, particularmente en las comunidades indígenas.

Esta cultura alrededor de la tierra genera vínculos que fomentan el arraigo territorial, el cuidado del medio ambiente, y se estrechan relaciones sociales a partir de la organización para el trabajo agrícola, principalmente en zonas indígenas y campesinas, aunque no puede obviarse que el ritmo de la modernización y los crecientes procesos urbanizadores, han mellado en la identidad campesina, en especial en las generaciones más jóvenes que optan por la migración y el trabajo asalariado ante las desventajas de los pequeños productores como la falta de impulso a la producción, la ausencia de precios de garantía, y la apertura comercial global, entre otras.

Con todo, se puede observar que la participación de la agricultura en la economía nacional ha ido disminuyendo, aunque a pesar de ello, la población económicamente activa del sector rural constituye cerca del $13 \%$, esto es, que la importancia del campo en el empleo es mayor que su peso en el valor de la producción.

Por otra parte, en los territorios de propiedad social, el principal producto que se cultiva en las tierras de riego y de temporal, es el maíz, cultivo originario de México que ha logrado adaptarse frente a plagas, temperaturas y suelos muy diversos, y que además de ser el principal cultivo para autoconsumo y comercial, genera también una identidad campesina. El maíz es un cultivo que no sólo se ha conservado, sino que ha sido mejorado con métodos tradicionales que van pasando 
de generación en generación a partir de los conocimientos ancestrales de los agricultores, de ahí su importancia en la tradición cultural de los pueblos campesinos y en la producción nacional. Sin embargo, el maíz como cultivo originario se encuentra amenazado debido a la introducción de cultivos de maíz transgénico en terrenos experimentales. ${ }^{7}$

Por otra parte, el deterioro del medio ambiente se expresa en el agotamiento de recursos locales y regionales a los que acceden las familias campesinas. La tierra también se cuenta como recurso en deterioro, pues la producción comienza a disminuir a causa del empleo de agroquímicos que provocan la erosión a mediano plazo, y aunado a esto, los productos encuentran un mercado interno prácticamente inoperante en el cual los precios ofrecidos a cambio de los productos, son insuficientes para garantizar la reproducción de la célula campesina, y frente al mercado internacional, la situación es de completa incompetencia. Cada año, según estimaciones de la $\mathrm{FAO}$, se pierden aproximadamente 25000 millones de toneladas de capa cultivable; mientras que alrededor de 2000 millones de hectáreas de suelo, equivalentes al $15 \%$ de la superficie continental (una superficie mayor que la de México y Estados Unidos juntos), han sido degradadas por actividades humanas (SEMARNAT, 2012).

Todo lo anterior, redunda en el cambio paulatino de los mercados de trabajo rurales. La migración, el cultivo de enervantes, la venta de la tierra ${ }^{8}$ y la terciarización de la economía rural son parte de estas transformaciones que se acompañan por la dinámica demográfica en una población rural que se encuentra en proceso de envejecimiento ${ }^{9}$.

Estas dinámicas de transformación en los patrones tradicionalmente campesinos, que se dedicaban exclusivamente a la producción agrícola y pecuaria, han generado también cambios en las comunidades campesinas a partir de que

para sobrevivir, el campesino, recurre a una serie de estrategias que a veces aparentan estar en contra de su propia historia, como son, el arrendamiento, venta o traspaso de sus parcelas ejidales, la subordinación productiva a los capitales agroindustriales y en el mejor de los casos, su asociación con empresarios agrícolas (BUSTAMANTE, 1994, p. 38).

Lo anterior, genera procesos de emigración temporal a tierras de agricultura comercial, de tal manera que se encuentran patrones de migración regional de campesinos empleados como jornaleros agrícolas que van desde el sur y sureste del país hacia el noroeste, siguiendo los ciclos de cultivos comerciales. También han engrosado la migración del campo a la ciudad desde mediados del siglo pasado; se han insertado en empleos eventuales como la construcción y el servicio doméstico (APPENDINI, 2009).

\footnotetext{
${ }^{7}$ Si bien las evidencias científicas sobre las consecuencias del consumo de productos transgénicos no han generado consenso, los transgénicos son semillas hechas en laboratorio en donde se cruza una semilla con otra especie, fabricadas por empresas trasnacionales. Por lo tanto, su introducción en los cultivos de los pequeños productores rurales generará mayor dependencia, y los procesos naturales de polinización, son un riesgo para la contaminación entre cultivos originarios y transgénicos, lo que puede generar problemas legales para los campesinos que no pueden comprobar los efectos de un intercambio natural de plantas, cuando las empresas requieren contratos para el uso de sus semillas. Al respecto puede verse el trabajo de ROBIN, 2008.

${ }^{8}$ El $66 \%$ de los 31, 514 ejidos registrados en México durante el Censo Ejidal 2007 (INEGI), ha sido vendido, de estas ventas, el $82 \%$ se han realizado entre ejidatarios, y el restante $17 \%$ se ha vendido a personas ajenas al ejido, avecindados y posesionarios.

${ }_{9}^{9}$ El $50 \%$ de los 4,210,830 ejidatarios tiene más de 55 años, según cifras del Censo Ejidal 2007, INEGI.
} 
Las respuestas frente a la crisis también han implicado la reconversión de la vocación productiva de las tierras a cultivos comerciales, la organización de los productores en asociaciones locales y regionales que generalmente se posicionan políticamente para demandar al Estado las garantías que les permitan mantener su condición campesina en mejores condiciones, hasta la potencial radicalización de los movimientos sociales que recurren al uso de las armas.

Aunado al proceso de desmantelamiento del estado y la emergencia de las políticas neoliberales, la soberanía alimentaria ha sido una estrategia cada vez más marginal para el proceso de desarrollo nacional. Así, cada vez son mayores las importaciones de alimentos, según datos del Banco de México retomados por Zúñiga:

\begin{abstract}
...la importación de alimentos se elevó a 42 mil 918.7 millones de dólares, hasta marzo de 2011, e implicó un incremento de 77.2 por ciento en los pagos hechos por la compra en el exterior de productos agropecuarios en un periodo similar de 52 meses del gobierno anterior (ZÚÑIGA, 2011, p. 15).
\end{abstract}

Los datos expuestos, no solamente impactan a nivel estructural en las finanzas gubernamentales, sino repercuten gravemente en la economía familiar, generando una amplia brecha de desigualdades económicas y sociales.

La importación de alimentos, además impacta en el cambio de dieta de los consumidores, pues en México $30 \%$ de los adultos padece obesidad y $69.5 \%$ tiene sobrepeso (OCDE 2010), mientras que cerca de 1 millón 600 mil niños, en su mayoría indígenas, padece desnutrición, y de los cuales uno de cada cinco sufre anemia crónica que afecta su desarrollo (VALDÉS, 2010, p. 23). Asimismo, ha habido un incremento acelerado en el precio de los alimentos, producto de distintos factores como la competencia inequitativa y las prácticas monopólicas, la producción de biocombustibles, y los efectos del cambio climático, entre otros.

Con todo, la seguridad alimentaria más que brindar garantías al derecho constitucional a la alimentación a través de la producción para el consumo interno, se encuentra en tal situación de vulnerabilidad que afecta con mayor intensidad a los campesinos e indígenas, pues según la Secretaría de Desarrollo Social, dos de cada tres personas que viven en el campo padecen una situación de indigencia. Esta situación se concentra principalmente en los estados de Guerrero, Oaxaca y Chiapas, donde se encuentran los índices más altos de desnutrición, pobreza y marginación.

De igual manera, la migración del campo en épocas recientes, está debilitando el tejido social comunitario, y generando transformaciones en los procesos identitarios y culturales, donde se encuentran pérdidas de tradiciones y costumbres conforme avanzan las generaciones. En otros términos,

...la emigración y el abandono del campo, son los efectos más dramáticos de la erosión espiritual y material que el capital ejerce sobre el tejido socioeconómico del mundo agrario, devastación tan irreversible y peligrosa como la que practica sobre los ecosistemas y recursos naturales (BARTRA, 2010, p. 59).

Hasta finales de los años ochenta, la migración internacional tenía por destino principalmente en ciertas áreas del territorio mexicano. Los estados con mayor tradición migratoria estaban concentrados en la región centro occidente del país, que comprende Zacatecas, Michoacán, Jalisco y Guanajuato, entre otros. 
Sin embargo, a partir de la década de los noventa la emigración internacional se da prácticamente en todo el país. Estados Unidos es, con mucho, el principal destino de los migrantes mexicanos. Sus flujos han crecido sustancialmente durante las últimas décadas, generando efectos en diversos aspectos económicos, políticos y sociales, en ambos lados de la frontera (UNGER, 2007, p.147).

Así, los fenómenos migratorios se han intensificado. Según datos del Banco de México, en 1990 las remesas internacionales captadas por nuestro país oscilaban alrededor de los 2490 millones de dólares, para 2007 esta cifra se elevó hasta 23979 millones de dólares, y en 2005, el estado de Michoacán fue el mayor receptor de remesas.

Cabe mencionar que esta migración, ha recaído principalmente en los jóvenes, muchos de ellos, habitantes de comunidades rurales, pues de acuerdo con el Censo Ejidal 2007, el $41 \%$ de los ejidos y comunidades en México, reportan la no permanencia de la mayoría de los jóvenes que tienen como destino la migración a Estados Unidos y las zonas urbanas en el interior del país, por lo tanto, hay una tendencia hacia el abandono del campo, que se acompaña del envejecimiento de la población rural.

A ese panorama, se suman las condiciones cada vez más riesgosas en el proceso migratorio, producto de fenómenos de corrupción y descomposición social en donde se encuentran involucrados distintos actores, tanto funcionarios gubernamentales como traficantes de personas y narcotraficantes, todos articulados en una compleja red que convierte a los migrantes en víctimas de extorsiones, secuestros e incluso asesinatos. Además, cabe mencionar que como producto de la crisis económica mundial, las remesas que los migrantes envían desde Estados Unidos hacia México, cayeron 15,74\% durante 2009, y aunque aparente han ido aumentando desde el segundo semestre de 2010, el poder adquisitivo en México disminuye año con año, por lo tanto, el dinero es insuficiente para adquirir todos los productos de la canasta básica, tanto el enviado por los migrantes, como el obtenido en el país.

\section{CONSIDERACIONES FINALES}

Una crisis recorre el mundo, y en México golpea fuertemente a los pequeños productores rurales desde los impactos del cambio climático hasta los impactos en las carencias a la mesa de cada hogar.

El papel del gobierno federal y los gobiernos locales se estima cada vez más distante de las necesidades de los grupos más vulnerables. En medio de todo, la relación entre gobierno y sociedad se encuentra en una crisis de confianza en las instituciones del Estado, y se observa la puesta en marcha de políticas públicas que se orientan hacia el libre mercado, la privatización de los servicios del Estado, y la desregulación de las acciones de gobierno.

A partir de lo expuesto, es necesario que las políticas públicas destinadas a la producción en pequeña escala, mantengan un diseño que además de empatar sus objetivos, accedan a un mayor porcentaje de la población que depende de la pequeña producción agropecuaria, de tal manera que no solamente se canalicen subsidios para la asistencia social, sino que detonen el papel de los productores como agentes para el desarrollo local y regional a través del incentivo a la producción con insumos, maquinaria, asistencia técnica, créditos e infraestructura al alcance de los pequeños productores, pero también en conjunto con la apertura de un mercado nacional que permita consolidad la seguridad y soberanía alimentaria.

Finalmente, las desigualdades sociales observan que la pobreza va en aumento, y que existe un amplio sector de la población que carece del acceso a 
servicios básicos. Si bien las políticas sociales que tienen un diseño interinstitucional procuran equilibrar esta situación, aun hace falta un esfuerzo más amplio de tal manera que la totalidad de la población acceda a los servicios que el Estado debe garantizar. La distribución del actual presupuesto destina grandes cantidades a la seguridad pública, hacia las instituciones electorales y los salarios de los trabajadores del Estado, empero, si bien todos estos asuntos son importantes, no menos importante es reactivar la economía local y revertir la marginación y pobreza que padecen los pequeños productores rurales.

El campo mexicano es cada vez más pobre y más desigual. En este campo, las mujeres, los jóvenes y los grupos indígenas se encuentran en el punto más delicado de la desigualdad de oportunidades para el desarrollo individual y colectivo. Este campo está envejeciendo y cada vez sufre más los efectos de la erosión ambiental pero también social.

Los retos para hacer frente a la crisis, implican el conjunto de esfuerzos de diversos actores de la sociedad, pero también requiere de un esfuerzo mayoritario de un gobierno que asuma la soberanía alimentaria como política de Estado.

La viabilidad de la pequeña producción agropecuaria, encuentra alternativas en nichos de productores que luchan contra la marginación de la que son objeto. Son ellos la evidencia de que otro campo es posible, de que el trabajo en pequeña escala aporta pasos firmes en la adaptación y mitigación del cambio climático, y de que es posible que en la mesa -suya y de los otros- haya productos más sanos, de que la tierra vale porque, a pesar de todo, la tierra sigue dando, y puede recuperarse para ofrecer un futuro mejor para las siguientes generaciones.

\section{REFERENCIAS BIBLIOGRÁFICAS}

ALLUB, L.; GUZMÁN, L. Las estrategias de sobrevivencia de los pequeños productores rurales de Jáchal, San Juan, Argentina. In: Estudios sociológicos. México. El Colegio de México. v. 18 n. 52 p. 125-165, enero/abril 2000.

APPENDINI, K.; DE LUCA, M. Estrategias rurales en el nuevo contexto agrícola mexicano, Roma: Organización de las Naciones Unidas para la Agricultura y la Alimentación. 2006.

APPENDINI, K.; TORRES, G. ¿Ruralidad sin agricultura? Perspectivas multidisciplinarias de una realidad fragmentada. México: El Colegio de México, Centro de Estudios Económicos. 2008.

BARTRA, A. Al alba: México y sus campesinos en el gozne de los tiempos. In: CONCHEIRO, L. et. al. Espacios públicos y estrategias campesinas ante la crisis en México. México: Universidad Autónoma Metropolitana unidad Xochimilco. 2010. p. 35-68.

BARTRA, A.; PARÉ, L. Polémica sobre las clases sociales en el campo mexicano. México: Macehual Cuadernos agrarios. 1979.

BUSTAMANTE, T. Estrategias de sobrevivencia campesina en los procesos de modernización agrícola. El caso de Tierra Caliente, Guerrero. In: Revista Economía teoría y práctica. México: Universidad Autónoma Metropolitana, n. 2. 1994 p. 211218 ,

CARTÓN, H. Nuevos actores y formas de representación social en el campo. In: PRUD'HOMME, J. El impacto de las políticas de ajuste en el campo mexicano. 
México: Instituto Latinoamericano de Estudios Transnacionales-Plaza y Valdés. 1995.

FEDER, E. Campesinistas y descampesinistas. Tres enfoques divergentes (no incompatibles) sobre la destrucción del campesinado. In: Revista Comercio Exterior, México. v. 27, n. 12, p. 1439-1446 diciembre, 1977.

GONZÁLEZ J.; GONZÁLEZ M. La tierra. Mitos, ritos y realidades. Barcelona: Antrhopos y Diputación Provincial de Granada.1992.

HERNÁNDEZ, E., Cosechan beneficios desiguales en el campo. Acessado em 12/12/2014. Disponível em: http://www.eluniversal.com.mx/nacion/175667.html

INEGI, Censo Agropecuario 2007. México: Instituto Nacional de Estadística, Geografía e Informática, 2009, p. 3-4 (Boletim Técnico 088/09).

INEGI, IX Censo Ejidal, Acessado em 12/12/2014. Disponível em: http://www.inegi.org.mx2007

INEGI, Censo de Población y Vivienda 2010, Acessado em 19/06/2014. Disponível em: http://www.censo2010.org.mx

KAUTSKY, K. La cuestión agraria, análisis de las tendencias de la agricultura moderna y de la política agraria de la socialdemocracia México: Siglo Veintino, 1974.

MORA J., Desarrollo y migración rural. In: YÚNEZ, A. Economía rural, México: E Colegio de México. 2010. p. 145-170.

OCDE, Obesity and the Economics of Prevention. Fit not Fat. Acessado em 15/06/2014. Disponível em: http://www.oecd.org

RAMOS, J. Hallan en Procampo corrupción, Acessado em: 15/09/14 Disponível em: http://www.eluniversal.com.mx/nacion/89796.html

ROBIN, M. El mundo según Monsanto: de la dioxina a los OGM, una multinacional que les desea lo mejor. España: Ediciones Península. 2008

ROBLES, H. Presupuesto para el campo. Acessado em: 15/09/14 Disponível em: http://subsidiosalcampo.org.mx/

SEMARNAT, Inventario Nacional de Suelos 2012. Acessado em: 12/06/2014 Disponível em: http://dgeiawf.semarnat.gob.mx

TARROW, S. El poder en movimiento. Los movimientos sociales, la acción colectiva y la política. Madrid: Alianza Universidad. 2004

UNGER, K. El desarrollo de las regiones de origen de los migrantes: experiencias y perspectivas. México: Centro de Investigación y Docencia Económicas. 2001

VALDÉZ, Blanca, Desnutridos, 1.6 millones de niños, Acessado em: 12/07/2014. Disponível em: http://www.promocion.salud.gob.mx/cdn/?p=137 
WOLF, E. Los campesinos. Barcelona: Labor. 1975.

YÚNEZ, A. Economía rural. México: El Colegio de México. 2010.

ZARAZÚA, J. et. al. El Programa de Apoyos Directos al Campo (PROCAMPO) y su impacto sobre la gestión del conocimiento productivo y comercial de la agricultura del Estado de México, In: Revista Agricultura, sociedad y desarrollo, Colegio de Postgraduados, México, v.8 n. 1, p. 89-105, ene./abr., 2011. 